\section{Economic impact of MIT spin-offs larger than Thailand's GDP}

[BOSTON] The substantial economic impact of the Massachusetts Institute of Technology (MIT) has been confirmed in a report which calculates that there are 4,000 active companies that were either founded by MIT graduates, faculty or staff, or were spun off from MIT laboratories.

Worldwide, these companies employed 1.1 million people in 1994, and generated $\$ 232$ million in sales. In the United States alone, MIT-related companies employ 733,000 people at more than 8,500 plants and offices, and account for one out of 170 jobs in the country.

Included are many top corporations, such as Campbell Soup, Digital Equipment Corporation, Gillette, Hewlett-Packard, Intel, McDonnell Douglas, Rockwell International, Raytheon and Texas Instruments.

The report, published last week, says that, if these corporations were to form an independent nation, their combined revenues would make it "the 24th largest economy in the world", with a gross domestic product between that of Thailand and South Africa.

The report is the first to assess the importance of an individual research university to the national economy, and it underlines the value of federal government support. "About 90 per cent of these companies have been founded in the past 50 years, in the period of the great research partnership between the federal government and research universities," says MIT's president, Charles Vest.

"The development of these business enterprises is one of the many beneficial spin-offs of federally funded research which has brought great advances in such fields as healthcare, computing and communications." Each year, about $\$ 370$ million is spent on research on the MIT campus, $\$ 270$ million of which comes from the federal government. Another $\$ 338$ million goes to research at the MIT-affiliated Lincoln Laboratories, primarily from the Department of Defense.

The study's director, Wayne Ayers, chief economist for BankBoston, says the study tried to explain how MIT has been so effective in generating new businesses in a "national economy that is increasingly emphasizing innovation". Factors cited by graduates who went on to start companies include encouragement from faculty mentors, access to the latest technology and an "entrepreneurial spirit" instilled by the university.

"MIT is not the only university that has had a national impact of this kind," says Ayers. But he says it is impossible to compare MIT's contribution to that achieved by other major research institutions until similar analyses are made.

SteveNadis

\title{
US seeks greenhouse gas cuts from the Third World
}

[IONDON] US delegates to the United Nations (UN) climate convention clashed with those from developing countries, the European Union (EU) and environmentalist groups last week over US proposals to include commitments from the developing world in a proposed protocol for reducing greenhouse gas emissions.

At present, only developed countries are required to reduce their greenhouse gas emissions, according to an agreement on the terms of a future protocol reached two years ago. The protocol itself has to be agreed at the next annual conference of the UN climate convention, which is due to be held in December in Kyoto, Japan.

But at a meeting of signatories to the convention in Bonn last week, at which countries presented their initial negotiating positions, the US delegation - apparently with one eye on potential difficulties in Congress - suggested that the original terms of the proposed protocol may need rewriting.

US officials have tabled suggestions that some developing countries should be encouraged to begin reducing their emissions voluntarily, with all countries taking some steps by 2005 - possibly according to a formula in which wealthier countries would make proportionately higher reductions, termed differentiation.

China, which leads the block of 77 developing countries known as the G77, has threatened to pull out of the talks unless the US proposal is withdrawn. Privately, however, some G77 delegates are understood to be attracted to the idea of differentiation between responsibilities as a possible basis for calculating commitments after Kyoto.

The EU, the Alliance of Small Island States (AoSIS) and environmentalist groups, such as the Climate Action Network, have also criticized the plans. They prefer the simpler, but politically more challenging, goal of a standard reduction in emissions for all developed countries only. They also want to avoid complicating talks further by ensuring that commitments from developing countries are not discussed until after Kyoto.

AoSIS and environmentalist groups favour the toughest measure: a 20 per cent cut in greenhouse emissions by 2005 . EU environment ministers announced a target of reducing emissions by 15 per cent of 1990 levels by 2010 . A 10 per cent reduction would be achieved through measures in individual countries (see figure, above right), with a further 5 per cent reduction through other policies and measures.

Australia, a large coal producer, and the oil-exporting countries are calling for com-

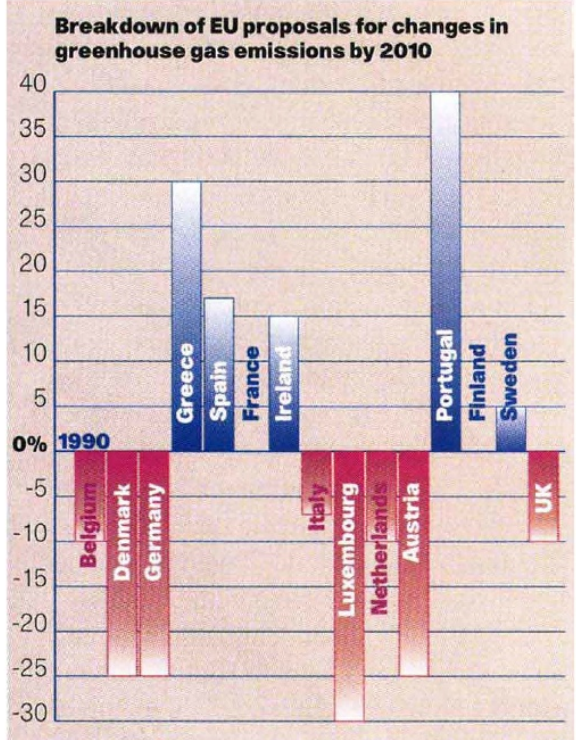

pensation for any revenues lost as a result of the protocol, which may force their customers to switch to 'greener' forms of energy.

One environmentalist group, the London-based Global Commons Institute, has emerged as a surprise supporter of the US plans which, it believes, "have the potential" for providing a more equitable basis of emissions reductions.

The institute's director, Aubrey Meyer, points out that the European position is also based on a form of differentiation, as poorer countries, such as Greece and Portugal, have been allowed to increase their emissions. He believes the US plan could "go far with one or two big G77 names" on its side.

But the prospect of reopening the terms of the protocol upsets campaigners such as Merylyn McKenzie Hedger of the World Wide Fund for Nature. "[This idea] risks stalling everything," she says. "Let's concentrate on what's achievable." Nevertheless she believes that a split in G77 ranks could increase support for a flat-rate reduction.

But one developed country delegate says the United States is unlikely to risk derailing the protocol. Rather, he believes the US plans are likely to help shape the terms of a future protocol that includes developing countries, but which will be settled after the Kyoto talks.

The US plan also supports the creation of a market in greenhouse emissions. Countries needing to make small reductions to meet a national target could agree to an extra reduction in exchange for cash or environmental technologies. A country purchasing this 'entitlement' could credit it towards its own emissions target. Another idea is to 'borrow' emissions from a future period to assist current compliance. Ehsan Masood 